\title{
Existing bridge evaluation using deficiency point method
}

\author{
Josef Vičan ${ }^{1, *}$, Jaroslav Repa ${ }^{1}$, and Peter Koteš ${ }^{1}$ \\ ${ }^{1}$ University of Žilina, Faculty of Civil Engineering, Department of structures and bridges, Univerzitná \\ 8215/1 Žilina, Slovakia
}

\begin{abstract}
In the transforming EU countries, transportation infrastructure has a prominent position in advancing industry and society. Recent developments show, that attention should be moved from the design of new structures towards the repair and reconstruction of existing ones to ensure and increase their satisfactory structural reliability and durability. The problem is very urgent because many construction projects, especially transport infrastructure, in most European countries are more than 50-60 years old and require rehabilitations based on objective evaluations. Therefore, the paper presents methodology of existing bridge evaluation based on reliability concept using Deficiency Point Method. The methodology was prepared from the viewpoint to determine the priority order for existing bridge rehabilitation.
\end{abstract}

\section{Introduction}

Bridges are considered an inseparable and strategic part of transport infrastructure, and they should not become the limiting components of communication capacity and traffic reliability. In the past, bridge maintenance, repair and rehabilitation activities were performed on an "as-needed" basis. This changed in the late 1960s, when a series of bridge failures focused public attention on the deterioration of existing bridges and motivated governments to initiate standardized bridge inspection and evaluation procedures. Data collected through these inspection activities formed the basis for computer-based bridge management systems (BMS), [1-3].

Evaluation of existing bridge structures is the most important process in the global BMS and provides basic information about existing bridges for decision-making processes related to the optimal bridge maintenance and rehabilitation strategy. The Department of Structures and Bridges prepared the new methodology based on the concept of reliability evaluation respecting the actual bridge load-carrying capacity and its real condition. The complex methodology of existing highway bridge evaluation was based on the Deficiency Point Method. Using the developed methodology, the priority order for existing bridge rehabilitation could be determined.

\footnotetext{
* Corresponding author: vican@,fstav.uniza.sk
} 


\section{Methodology of existing bridge evaluation}

To determine the priority order for existing bridge rehabilitation, the development of the methodology for bridge complex evaluation shall be assumed. It was a long-term problem of the research activities of the Department of Structures and Bridges in frame of research supported by Slovak Research and Development Agency [4] based on the previous activities in frame of the applied research for Slovak Road Administration (SRA) [5] or Slovak Railways (SR) [6]. The idea of the bridge reliability evaluation was presented in this research that prefers the existing bridge reliability as the main parameter of the bridge evaluation. The safety is the basic and the most significant attribute of the structural reliability. In the case of existing bridge structure, the reliability is quantitative expressed by its load-carrying capacity taking into account the bridge actual condition. Therefore, the unified methodology of the bridge load-carrying capacity calculations for existing highway bridges [5] and railway bridges [6] based on the partial safety factor method were developed in frame of applied research activities for SRA and SR. Nevertheless, the bridge evaluation using its load-carrying capacity only does not enable allowing for all existing bridge deficiencies which could influence another reliability attributes, especially parameters related to the bridge serviceability. Among those deficiencies, e.g. the insufficient spatial arrangement on or under the bridge should be included. The influence of those parameters shall be solved separately, so that the evaluation objectivity is reduced due to the need to determine weighting factors for both or more evaluating parameters affecting existing bridge evaluation. From this viewpoint, we have tried to develop the most complex bridge evaluation in frame of above mentioned research project [4] based on the concept introduced in previous research activities $[5,6]$.

The methodology proposal was based on Deficiency Point Method taking into account four basic evaluation parameters - actual bridge load-carrying capacity, actual bridge deck width, actual bridge vertical clearance and actual bridge age. Two secondary parameters road traffic intensity and detour length due to insufficient load-carrying capacity or inconvenient bridge arrangement were also considered in the first methodology proposal. Respecting results of the project entrance disputation and actual approaches to the determination of highway bridge load-carrying capacity, where simplified methods and estimations are preferred, the number of evaluating parameters had to be extended taking into account the effect of actual bridge condition determined by regular bridge inspections. At present, this parameter is considered as the main evaluating parameter in the case of highway bridges and decision-making processes related to maintenance strategy and bridge rehabilitation are mostly based on this parameter.

Due to questionable determination of the detour length in the case of insufficient bridge load-carrying capacity or bridge arrangement, this secondary parameter was replaced by other parameter allowing for the actual bridge length. Thus, the resulting number of the main evaluating parameters was increased to five, as follow:

- Actual bridge load-carrying capacity $\left(B_{L C}\right)$.

- Actual bridge technical condition evaluated according to [7] $\left(B_{T C}\right)$.

- Actual bridge deck width $\left(B_{D W}\right)$.

- Actual vertical bridge clearance over and under the observed bridge $\left(B_{V C}\right)$.

- Actual bridge age and its planned remaining lifetime $\left(B_{R L}\right)$.

Two secondary parameters complete the bridge significance from the transportation and building viewpoint:

- Parameter of road traffic intensity replacing bridge categorization according to road classification.

- Parameter of the bridge length underlining bridge significance from the building and economical viewpoint. 


\section{Deficiency point method}

General mathematic formulation of the deficiency points calculation of the bridge evaluated is given by the following equation

$$
D P=\Sigma\left[W_{i} \cdot f_{i}(a, b, c, d, e) \cdot W_{j} f_{j}(\mathrm{f}, \mathrm{g})\right]
$$

$W_{i} \quad$ are the weighting factors defined for main individual evaluating parameters according to its significance.

$f_{i}(a, b, c, d, e)$ expresses mathematic interpretation of the individual main parameter influence.

$a, b, c, d, e$ are the individual main evaluating parameters.

$W_{j} \quad$ are the weighting factors defined for secondary individual evaluating parameters.

$f_{i}(g, f) \quad$ represents the mathematic formulation for influence of the individual secondary evaluating parameters.

$g, f \quad$ are the secondary evaluating parameters.

In the evaluation model presented above, the general equation (1) can be written in following form

$$
D P=W_{L C} B_{L C}+W_{T C} B_{T C}+W_{D W} B_{D W}+W_{V C} B_{V C}+W_{R L} B_{R L}
$$

$D P \quad$ is the resulting number of deficiency points of the evaluated bridge.

$B_{L C} \quad$ is the number of deficiency points due to actual bridge load-carrying capacity.

$B_{T C} \quad$ is the number of deficiency points taking into account the bridge actual technical condition.

$B_{D W} \quad$ is the number of deficiency points allowing for actual bridge deck width.

$B_{V C} \quad$ is the number of deficiency points allowing for actual bridge vertical clearance over and under the bridge observed.

$B_{R \mathrm{~L}} \quad$ is the number of deficiency points from the bridge age viewpoint.

$W_{j} \quad$ are the weighting factors of individual main evaluating parameters from the viewpoint of their influence on the complex bridge evaluation.

Mathematic interpretations of the individual evaluating parameters are introduced in following chapters.

\subsection{Effect of the actual bridge load-carrying capacity}

Effect of the actual bridge load-carrying capacity should be expressed by following formula

$$
B_{L C}=\left(\frac{V_{n, \max }-V_{n}}{V_{n, \max }}\right)\left(W_{T} K_{T}+W_{L} K_{L}\right)^{n_{1}}
$$

but $B_{L C} \geq 0$ and

$V_{n, \max }$ is the maximum characteristic value of the bridge normal load-carrying capacity expressed in tons.

$V_{n} \quad$ is the bridge actual normal loading capacity in tons.

$n_{l} \quad$ is the exponent allowing for classification of the highways.

$W_{T} \quad$ is the weighting factor of the bridge road traffic intensity effect.

$W_{L} \quad$ is the weighting factor of the bridge length effect.

$$
W_{T}+W_{L}=1.0
$$


$K_{T} \quad$ is the factor taking into account the effect of the bridge traffic intensity.

$$
K_{T}=n_{2}\left(\frac{A D I-A D T I}{\max D I}\right)+n_{3}\left(\frac{A D T I}{\max D I}\right)
$$

$A D I \quad$ is the average daily highway traffic intensity on the observed bridge (vehicles per day).

$A D T I \quad$ is the average daily truck traffic intensity on the observed bridge.

$\max D I$ is the maximum daily highway traffic intensity in the evaluated region.

$n_{2}, n_{3} \quad$ are factors allowing for effects of the automobile or truck traffic, $0 \leq n_{2} \leq$ 1.0 and $0<n_{3} \leq 1.0$.

$K_{L} \quad$ is the factor taking into account the effect of the bridge length and should be determined according to formula

$$
K_{L}=\frac{B L}{\max B L}
$$

$B L \quad$ is the actual bridge length.

$\max B L$ is the maximum bridge length in the evaluated part of highway, region, etc.

\subsection{Effect of the bridge technical condition}

Effect of the bridge actual technical condition should be expressed by following formula respecting the system of evaluating bridge technical condition in accordance with standard [7]

$$
B_{T C}=\left(1-\frac{7-T C}{4}\right)\left(W_{T} K_{T}+W_{L} K_{L}\right)^{n_{1}}
$$

but $B_{T C} \geq 0$ and $T C>3$,

$T C$ is the evaluation of the bridge actual technical condition according to [7] defined by numbers from 1 till 7 .

In compliance with [7], the parameter $B_{T C}$ respects only bridges classified by $T C>3$, whose deficiencies could affect bridge load-carrying capacity.

\subsection{Effect of the bridge arrangement}

In this case, the effect of the bridge deck width and bridge vertical clearance should be distinguished. The number of the deficiency points related to the bridge deck width can be calculated according to formula

$$
B_{D W}=\left(\frac{S D W-D W}{S D W}\right)\left(W_{T} K_{T}+W_{L} K_{L}\right)^{n_{1}}
$$

but $B_{D W} \geq 0$ and

$S D W$ is the standard bridge deck width in accordance with standards [8, 9].

$D W \quad$ is the actual bridge deck width. 
The ranking formula for bridge vertical clearance is in two components to account for traffic over and under the bridge and can be written in following form

$$
B_{V C}=0.5\left(V C_{0}+V C_{u}\right)\left(W_{T} K_{T}+W_{L} K_{L}\right)^{n_{1}}
$$

but $B_{V C} \geq 0$ and

$V C_{o} \quad$ expresses effect of the bridge vertical overclearence.

$V C_{u} \quad$ expresses effect of the bridge vertical underclearence.

Effect of the bridge vertical overclearence could be determined in accordance with formula

$$
V C_{o}=\frac{S V O C-V O C}{S V O C}
$$

but $V C_{o} \geq 0$ and

SVOC is the standard bridge vertical overclearence according to [8].

$V O C$ is the actual bridge vertical overclearence.

Effect of the bridge vertical underclearence could be determined in accordance with the following equation

$$
V C_{u}=\frac{S V U C-V U C}{S V U C}
$$

but $V C_{u} \geq 0$ and

$S V U C$ is the standard bridge vertical underclearence according to [8].

$V U C$ is the actual bridge vertical underclearence.

\subsection{Effect of the bridge age}

From the viewpoint of this evaluation parameter, the aim was to allow for bridge remaining lifetime. Bridge remaining lifetime is the very significant parameter from the viewpoint of the existing bridge rehabilitation. Because of complicated calculation of the bridge remaining lifetime due to various type of material degradation, currently not knowing, the actual bridge age was finally considered for this parameter only. Then, the effect of the bridge age should be expressed by formula

$$
B_{R L}=\left[1-\left(\frac{B C+T_{D}-B E}{T_{D}}\right)\right]\left(W_{T} K_{T}+W_{L} K_{L}\right)^{n_{1}}
$$

but $B_{R L} \geq 0$ and

$T_{D} \quad$ is the design bridge lifetime considered as 100 years.

$B C$ is the year of the bridge construction or reconstruction.

$B E \quad$ is the year of the bridge evaluation.

\subsection{Calibration of the parameter weights}

The methodology presented above was processed for computational utilization. The first software version was prepared using table processor Excel, in which the methodology was tested and the optimal choice of the weighting main and secondary factors was found by means of the parametric studies. In frame of the parametric studies, the data files of the 96 bridges from Žilina region, 72 bridges from the region of Banská Bystrica and 16 bridges 
from Košice region were tested. The following value of the weighting factors were recommended for practical use in frame of Slovak Road Administration as the outputs of the performed parametric studies

- Effect of the bridge loading capacity

- Effect of the bridge actual technical condition

$W_{L C}=45$

- Effect of the bridge deck width

$W_{T C}=30$

- Effect of the bridge vertical clearance

$W_{D W}=10$

- Effect of the bridge age

$W_{V C}=5$

- Effect of the highway traffic intensity

$W_{R L}=10$

- Effect of the bridge length

$W_{T}=0.8$

- Effect of the highway classification

$W_{L}=0.2$

- Effect of the highway truck traffic intensity

$n_{l}=0.5$

- Effect of the highway automobile traffic intensity

$n_{2}=1.0$

$n_{3}=1.0$

\section{Conclusions}

The contribution presents results of the research project elaborated in frame of applied research related to existing bride evaluation. Methodology of the complex existing bridge evaluation was developed based on the Deficiency Points Method. Using the methodology, the priority order for existing bridge rehabilitation could be determined.

The paper presents results of the research project APVV-14-0772 supported by the Slovak Research and Development Agency and the project 012ŽU-4/2016 supported by the Cultural and Education Agency of Slovak Republic.

\section{References}

1. J. Lauridsen, J. Bjerrum, N.H. Andersen, B. Lassen, Struc. Eng. Inter. 3, 216-220 (1998)

2. P.D. Thompson, E.P Small, M. Johnson, A.D. Marshall, Struc. Eng. Inter. 4, 303-308 (1998)

3. J. Vičan, Bridge Management System - Methodology of the Existing Road Bridge Evaluation, Final Report for Slovak Road Administration (University of Žilina, Žilina, 1998)

4. J. Vičan at all, Evaluation methodology of existing bridges, Project of the SRDA APVV-0106-11 (University of Žilina, Žilina 2015)

5. J. Vičan at all, Bridge Management System (Ministry of Transportation of Slovak Republic, Bratislava, 2003)

6. J. Vičan at all, Program of planning maintenance and repair of infrastructure for project of the transformation and restructuralization of Slovak Railways (University of Žilina, Žilina, 2001)

7. OTN 736220 , Bridge evidence on the motorways, roads and local communications (SOSMT, Bratislava, 1993)

8. STN 73 6201, Standard specifications for bridges (SOSMT, Bratislava, 1999) 